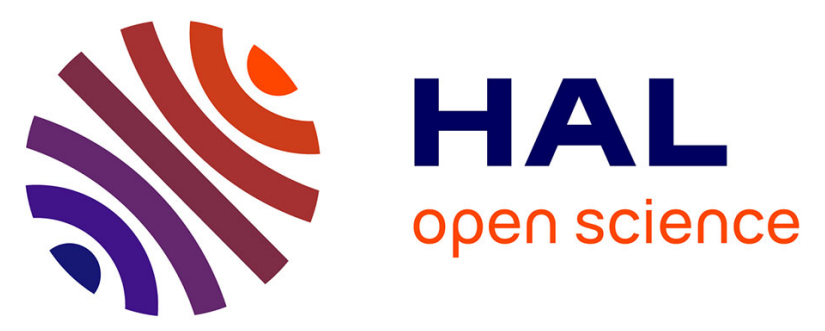

\title{
Lung density measurement in postmortem computed tomography: a new tool to assess immediate neonatal breath in suspected neonaticides
}

\author{
Mathilde Ducloyer, Lucile Tuchtan, Clémence Delteil, Marie-Dominique
}

Piercecchi, Arthur David, Guillaume Visseaux, Renaud Bouvet, Guillaume

Gorincour, Renaud Clement

\section{To cite this version:}

Mathilde Ducloyer, Lucile Tuchtan, Clémence Delteil, Marie-Dominique Piercecchi, Arthur David, et al.. Lung density measurement in postmortem computed tomography: a new tool to assess immediate neonatal breath in suspected neonaticides. International Journal of Legal Medicine, 2020, 10.1007/s00414-019-02103-3 . hal-02493102

\section{HAL Id: hal-02493102}

\section{https://hal-univ-rennes1.archives-ouvertes.fr/hal-02493102}

Submitted on 27 Feb 2020

HAL is a multi-disciplinary open access archive for the deposit and dissemination of scientific research documents, whether they are published or not. The documents may come from teaching and research institutions in France or abroad, or from public or private research centers.
L'archive ouverte pluridisciplinaire HAL, est destinée au dépôt et à la diffusion de documents scientifiques de niveau recherche, publiés ou non, émanant des établissements d'enseignement et de recherche français ou étrangers, des laboratoires publics ou privés. 
Title page

Title:

Lung density measurement in post-mortem computed-tomography: a new tool to assess immediate neonatal breath in suspected neonaticides.

Authors :

Mathilde DUCLOYER ${ }^{1,2}$, Lucile TUCHTAN ${ }^{3,4}$, Clémence DELTEIL ${ }^{3,4}$, Marie-Dominique PIERCECCHI $^{3,4}$, Arthur DAVID ${ }^{2}$, Guillaume VISSEAUX ${ }^{1}$, Renaud BOUVET ${ }^{5}$, Guillaume GORINCOUR $^{6}$, Renaud CLEMENT ${ }^{1}$

${ }^{1 .}$ Forensic Medecine Department, Centre Hospitalier Universitaire de Nantes, Nantes, France

2. Department of Radiology, Centre Hospitalier Universitaire de Nantes, Nantes, France

3. Forensic Medicine Department, APHM, Hopital de la Timone, Marseille, France

4. CNRS, EFS, ADES Aix Marseille Université, Marseille, France

5. Forensic Medicine Department, Centre Hospitalier Universitaire de Rennes, Université de Rennes 1, IDPSP EA 4640, Rennes, France

6. Laboratoire d’Imagerie Interventionnelle et Expérimentale, LiiE, EA4264, Aix Marseille Université, Marseille, France 
$\underline{\text { ORCID Identifiers: }}$

Mathilde DUCLOYER 0000-0003-1116-4943

Lucile TUCHTAN 0000-0001-6248-2840

Clémence DELTEIL 0000-0001-5171-8520

Arthur DAVID 0000-0002-6401-0035

Renaud BOUVET 0000-0003-3002-6829

Guillaume GORINCOUR 0000-0002-4926-1063

Renaud CLEMENT 0000-0002-5254-4611

\section{Corresponding author:}

Mathilde DUCLOYER,

Forensic Medicine Department, Centre Hospitalier Universitaire de Nantes, Bâtiment Jean Monnet, 30 Boulevard Jean Monnet, 44000 Nantes Cedex, France

Mathilde.ducloyer@chu-nantes.fr

Phone Number: +33 635504921

\section{Acknowledgements:}

The authors gratefully acknowledge Professor Michel DURIGON and Doctor Caroline RAMBAUD for their technical advice and their experience, Doctor Guillaume TURC for his statistical contribution, Professor Bertrand LUDES and Doctor Laurence LEGRAND for their responsiveness.

Conflict of interest: The authors declare that they have no conflict of interest.

Keywords: Neonaticide; post-mortem Computed-Tomography; lung density; stillbirth; livebirth 
Abbreviations: CT: computed-tomography; PMCT: post-mortem computed-tomography; HT: hydrostatic test; HU: Hounsfield units; CI: confidence interval; ICC: intraclass coefficient; ROI: region of interest; HES: Hematein Eosin Saffron

\section{Abstract}

Intro Evidence of breath after birth is one of the main forensic issues in suspected neonaticide. Hydrostatic test (HT) and pathological examination are currently used to assess it, but they are not entirely reliable or immediately available.

Objectif To determine the performance of post-mortem computed-tomography (PMCT) to assess neonatal breath in suspected neonaticide, by comparing lung CT attenuation values between livebirth and stillbirth cases, in correlation with HT and pathology.

Method Cases of suspected neonaticides who underwent a PMCT and complete forensic autopsy with an HT were retrospectively selected from the databases of Four French Forensic Medicine Departments. The diagnosis of vitality (i.e. stillbirth or livebirth) was based on the pathological examination and/or a combination of arguments, including HT result. Lung density on CT was measured in Hounsfield Units (HU) by ROIs drawn in both pulmonary parenchyma.

Results Eleven patients were included, six livebirth and five stillbirth cases. The result of HT was concordant with pathological examination when available (seven cases). Mean lung densities in livebirth cases (- $173 \mathrm{HU}$ [-255; -91 CI 95\%]) were significantly lower than in stillbirth cases (40 HU [28; 52 CI 95\%]) $(\mathrm{p}<0.05)$, with a very high degree of interobserver reproducibility $($ ICC $=0.998$ (CI 95\% 0.991-0.999; $\mathrm{p}<0.001)$.

Conclusion PMCT and especially lung CT attenuation measurement is a reliable and easy-touse method for assessing neonatal breath in suspected neonaticides. 


\section{Introduction}

Neonaticide was defined by Resnick [1] in 1970 as the killing of a child during its first 24 hours of life. The mother is mostly involved and the killing typically occurs after a concealed or denied pregnancy [2,3]. The exact rate of neonaticide is by definition unknown and probably underestimated [4]. The main question of the magistrate in this situation is: was the child alive at birth (livebirth) or not (stillbirth)? The answer is provided by the evidence of effective and spontaneous respiratory movements after birth. Indeed, in France as in many countries, the first inspirations of a newborn result in it passing from the status of a foetus to the status of a child, changing the legal considerations.

Two main tools are currently used to assess neonatal breath. First, the hydrostatic test (HT) also called "docimasia” or "lung floating test”, has been used for centuries [5]. If the baby has breathed, the lungs float when immersed in water and the test is considered as "positive". If he or she has not, the lungs sink and the test is "negative". This test has always been very controversial [6], mainly due to false positives, attributed to putrefaction and cardiopulmonary resuscitation (CPR). False negatives can occur in pulmonary pathologies. The second method is pathological analysis, considered to be the gold standard and usually performed to confirm alveolar expansion. However, its results are not immediately available as conditioning takes several weeks. In recent years, post-mortem computed-tomography (PMCT) has been developed in routine forensic practice and may represent a useful complementary tool to help the forensic pathologist, but its ability to address key issues of neonaticide is not yet fully documented.

The aim of this work was to determine the performance of PMCT to assess neonatal breath in cases of suspected neonaticides, especially by comparing lung CT attenuation values between livebirth and stillbirth cases. 
Patients and Methods

\section{$\underline{\text { Population and clinical data collected }}$}

We retrospectively selected cases of suspected neonaticide who underwent a complete forensic autopsy with hydrostatic test and a PMCT in four French Forensic Medicine Departments between March 2012 and September 2018. We secondarily excluded cases with signs of putrefaction. We noted elements of anamnesis, i.e. whether CPR was performed, the estimated delay between birth and the discovery of the body, and specific data from the autopsy, i.e. the post mortem changes, the estimated gestation term, lungs aspect and weight, modality of HT and its result, and the conclusion of the forensic pathologist about the cause of death.

We systematically searched whether a histopathological analysis was performed and considered its conclusion about alveolar expansion and the cause of death.

The conclusion about the vitality of the child (livebirth or stillbirth) was based on the microscopic findings when available and/or on the combination of clinical anamnesis, lungs aspect and HT results.

\section{$\underline{\text { PMCT }}$}

Bodies were scanned using different multislice CT scanners (Optima CT 660, Lightspeed VCT, Revolution EVO; GE Healthcare; Chicago, Illinois, USA / Aquillion Prime, Canon, Tokyo, Japan / Somatom Definition; Siemens, Munich, Germany). Data acquisition was performed in the axial plane, with a tube voltage of 120 to $140 \mathrm{kV}$ and $1 \mathrm{mAs}$ to $90 \mathrm{mAs}$. Slice thickness ranged from $0.625 \mathrm{~mm}$ to $1.25 \mathrm{~mm}$. Reconstructions were made using soft and bone filters. PMCT images were analysed on a Carestream ${ }^{\circledR}$ workstation by a forensic radiologist with multiplanar and volume rendered (VR) reconstructions on the chest and the abdomen. 
Aeration of the pulmonary parenchyma of the newborns was determined by a qualitative visual appreciation and ranked as: present, absent or possible.

We then evaluated the CT attenuation values of pulmonary parenchyma by measuring mean and extreme values of density per voxel of the parenchyma in Hounsfield units (HU) by tracing manually three "regions of interest" (ROIs) on the superior, middle and inferior regions in the axial plane. The ROIs were as wide as possible considering chest size, excluding pulmonary hilum. The global mean density of each pulmonary field was calculated as the mean of the six average densities collected. Measures were performed independently by the forensic radiologist and a forensic pathologist.

We also evaluated the aeration of trachea and bronchi and the presence of gas in the stomach and gastro-intestinal tract. Finally, we noted the position of the two diaphragmatic cupola in relation to the ribs, assuming that the breathing could modify their height.

\section{$\underline{\text { Statistical analyses }}$}

All statistical analyses were performed using Microsoft ${ }^{\circledR}$ Excel ${ }^{\circledR} 2016$ (Microsoft Corp. Redmond, WA, USA). Quantitative variables were reported as mean, standard deviation and range. The mean densities of lung parenchyma measured in stillbirth cases were compared to those measured in livebirth cases using a Student's t-test. An intraclass correlation coefficient (ICC) was used to evaluate the reproducibility of lung density measurements. Results were considered significant for $\mathrm{p}<0.05$ (two-sided).

\section{$\underline{\text { Ethical considerations }}$}

The present study's research protocol was established in accordance with the Helsinki Declaration on Medical Research. 
Results

\section{$\underline{\text { Population and autopsy findings }}$}

Twelve cases were identified. One case was excluded because of advanced signs of decomposition, with presence of diffuse gas in intravascular and soft tissue spaces at PMCT (Radiological Alteration Index > 50 [7]), confirmed by external and internal examination. Eleven cases were therefore included in our study. Two cases received specialized CPR. The interval between birth and the discovery of the body was estimated at less than 36 hours in eight cases, based on the testimonies and the police investigation. It was unknown in the three other cases. One case showed signs of maceration at the external inspection and an overlap of the skull bones on CT scan, which could be compared to a Spalding's sign [8]. There were no external or internal signs of putrefaction reported or visible on CT in the 10 remaining cases. The mean gestation age was 36 weeks of amenorrhea, ranging from 26 to 41, determined by the mensuration of head circumference, body height and in some cases by the length of long bones, measured on CT scan. Five cases were considered to be "full-term" babies. There was no significative difference between the mean gestational age in livebirth and stillbirth (i.e. 37 and 33 weeks of amenorrhea, respectively; $\mathrm{p}=0.2$ ). Hydrostatic test was systematically performed, by diving the lungs into water. It was "positive" in six cases and "negative" in five cases. We noted some differences in the modus operandi between centres. The whole thoracic block, which included the two entire lungs, the heart and the thymus, was tested in four cases, the entire lungs separately in four cases. The technique wasn't specified in three cases. The characteristics of the population and the autopsy findings are presented in Table 1.

\section{$\underline{\text { Pathological examination }}$}


Pathological examination including lungs' description was performed on seven cases. The pulmonary alveoli were described as expanded in four cases and not expanded in the other three. (Figures 1-3). The conclusions of the pathologists were always concordant with the result of HT. One case died of a massive meconium inhalation, with areas of condensation and acute emphysema. Two babies possibly deceased of mechanical asphyxia. No pulmonary pathology or cardiac disease was found as a cause of death in other cases.

\section{$\underline{\text { Conclusion about vitality }}$}

The final conclusion was livebirth in six cases and stillbirth in five cases.

\section{$\underline{\text { PMCT findings }}$}

Visual appreciation of the pulmonary parenchyma aeration was "absent" in 4/5 stillbirth cases, "present" in 5/6 livebirth cases (Figures 1 and 2) and "possible" in the two remaining cases (one livebirth, one stillbirth) who received CPR (Figure 3 and 4). Mean lung densities in livebirth cases (- 173 HU [-255; -91 CI 95\%]) were significantly lower than in stillbirth cases (40 HU [28; 52 CI 95\%]) $(\mathrm{p}<0.05)$. These results are summarized in Figure 5. The two cases for which the aeration was considered as "possible" at the first reading had a global density concordant with these results, as the parenchyma's density was positive ( $25 \mathrm{HU}$ ) for the stillbirth child and negative (- 90 HU) for the livebirth child.

Regarding the interobserver reproducibility of the measurements, the ICC was 0.998 (CI 95\% 0.991-0.999; $\mathrm{p}<0.001)$.

The trachea and bronchi were aerated in five cases (3/5 i.e. $60 \%$ of livebirths, $2 / 6$ i.e. $33 \%$ of stillbirths). Air was present in the stomach in all cases but noted in the gastro-intestinal tract further than the duodenojejunal junction only in four cases, the two in which a CPR was performed and two children born alive, i.e. $27 \%$ of all cases born alive. There was no difference in the height of the diaphragm between the livebirth and stillbirth cases: the right 
cupola was always noted between the fifth and sixth rib and the left cupola between the sixth and the seventh rib. PMCT findings are resumed in Table 2.

\section{Discussion}

The development of postmortem imaging has brought many perspectives for post-mortem explorations [9], especially in perinatology [10]. It has become a reliable, non-invasive and available tool in addition to conventional autopsy techniques. In case of neonaticide, the potential of PMCT has already been approached to assess live birth, but the previously published series contain very few cases [11] or with advanced signs of putrefaction [12].

The present study is the first to show that PMCT measurement of lung density can easily be used to assess neonatal breath in cases of suspected neonaticide. Our results demonstrate that children born alive have a mean lung density significantly lower than stillbirths. Conversely, the aeration of the trachea and bronchi and diaphragmatic height seem not to be reliable signs to use in corroborating the hypothesis of vitality. This work was based on a larger number of cases than previously reported, with a homogeneous repartition, considering the number of stillbirth and livebirth cases (five and six cases respectively), pulmonary maturity (with a mean gestational age of 33 and 37 amenorrhea weeks respectively) and the post-mortem changes (no sign of putrefaction).

In 2013, Michiue et al. measured CT attenuation values of pulmonary parenchyma in this setting [13]. Their case series included three livebirth cases, one stillbirth case with CPR and three stillbirth cases without CPR. As in our study, their stillbirth cases had positive mean CT densities. However, only one of their livebirth cases had a negative mean density. Indeed, the two other children born alive died from pulmonary distress and cardiac failure. These two pathologies increased CT lung density, due to oedema and atelectasis. Contrarily, none of the 
subjects in our series, except one, died as a result of an identified cardiac or pulmonary cause susceptible to change lung appearance and CT density.

Besides, the method we describe is simple, little time-consuming and does not require specific software nor complex image post-processing. Its main limitation is the difficulty of discriminating mediastinum from the lungs to draw the ROIs when the parenchyma was completely non-aerated. The distribution of gas in the gastro-intestinal tract was also very easy to identify. As previously described $[13,14]$, the presence of gas in the gastro-intestinal tract is commonly admitted as a sign of extra-uterine life. We systematically noted the presence of at least one bubble of gas in the stomach, even in stillbirth cases. However, the presence of air located further along than the duodenojejunal junction was only noted in children born alive and/or who received CPR. In our opinion, the aeration of the small intestine can, therefore, be considered as evidence of liveborn when present, except after CPR. In contrast, a small amount of air in the stomach may not be used to assess extrauterine life.

We highlighted a good reliability of the hydrostatic test, with a good agreement with the pathological examination, as previously reported[15]. Yet, we noted a certain variability in the practices, as either the lungs only or the entire thoracic block were evaluated; the liver or gastro-intestinal tract were never tested. Generally, HT is almost always performed during the autopsy of a deceased newborn [16] and is often mentioned in manuals of forensic science $[14,17,18]$ but the exact protocol to carry it out is rarely detailed. In 1997, Moer [19] identified several techniques and found that the most reliable option was to immerge the whole lung, compared to the macroscopic appearance, the liver test and the compression test. The immersion of a piece of liver is used as a control to avoid misinterpretation of the HT due to the presence of putrefaction gas [11]. The interest of this practice could be discussed, as 
PMCT is very efficient in evaluating the presence of intravascular gas due to putrefaction [11, $20]$ or any other cause [21, 22].

Pathological examination confirms or invalidates the presumptions made by the HT and thus represents the gold standard for the diagnosis of vitality [14]. Macroscopic inspection first notices the global aspect of lungs which are compact and dark red in stillbirth but rose with visible lobules in livebirth. Microscopic examination then seeks to identify the unfolding of bronchial and alveolar lumen. It can also rule out the main differential diagnoses (pneumonia, hyaline membrane disease) likely to negate the HT. Artefacts due to putrefaction (with vacuole parenchymal lysis that can mimic alveolar expansion) and CPR (ruptures of interalveolar walls) must in particular be known [23].

Only one case on 12 (8\%) presented advanced putrefactive signs and was thus initially excluded. The literature data reports a rate of $32 \%$ of decomposed bodies in this context [16]. The alteration of the body due to putrefaction is currently known to considerably interfere with both HT and PMCT and prevents all possibility of diagnosing neonatal breath [12]. Our only putrefied case presented a similar difficulty as HT was falsely positive and no cause of death was identified.

The diagnosis of vitality is always questionable in children with CPR. Two cases of our series received CPR, for which aeration on PMCT was considered as "possible”. Measurement of lung parenchyma density was, however, clearly different (positive for the stillbirth case and negative for the livebirth case) and consistent with the diagnosis of vitality. We could hypothesize that, in doubtful cases, CT lung density measurement could help to achieve the final diagnosis. More cases would be needed to confirm this trend. Indeed, post-mortem ventilation could theoretically be the cause of the presence of air in the lung parenchyma. It is therefore classically suspected to be responsible for false positive HT [6] and could modify microscopic examination. Pathologist and radiologist must consequently remain cautious in 
their conclusions and consider the possible role of CPR on the aspect of the parenchyma. On a prospective study, controlled post-mortem ventilation has been studied as a tool to improve the interpretation of PMCT parenchymal abnormalities in adults [24]. Although it appears that ventilation decreases the density of lung parenchyma, due to the clearing of livor mortis and hypostasis, it doesn't seem to affect the appearance of the pathological lung. This would suggest that post-mortem ventilation alone would not be sufficient for complete and satisfactory lung aeration in case of stillbirth. Nevertheless, as suggested by other authors evaluating MRI performance in this setting [25], a further study on pulmonary PMCT density after post-mortem ventilation in cases of stillbirths is necessary to confirm this hypothesis.

\section{Conclusion}

This work highlights the importance of PMCT in suspected neonaticides. Lung density measurement seems to be a reliable and reproducible tool to help the forensic pathologist assess breathing after birth, in addition to autopsy and histopathology. Nowadays, CPR still remains a limit in interpreting PMCT and HT results.

Besides, PMCT analysis of pulmonary parenchyma remains challenging for the forensic radiologist [26, 27], especially in children [28, 29]. The description of the "normal lung" in deceased newborns or in neonatal period would, therefore, be an interesting perspective for a better analysis of lung parenchyma in suspected neonaticide. 
References

1. Resnick PJ (1970) Murder of the Newborn: A Psychiatric Review of Neonaticide. Am J Psychiatry 126:1414-1420. https://doi.org/10.1176/ajp.126.10.1414

2. Makhlouf F, Rambaud C (2014) Child homicide and neglect in France: 1991-2008. Child Abuse Negl 38:37-41. https://doi.org/10.1016/j.chiabu.2013.08.016

3. Vellut N, Cook JM, Tursz A (2012) Analysis of the relationship between neonaticide and denial of pregnancy using data from judicial files. Child Abuse Negl 36:553-563. https://doi.org/10.1016/j.chiabu.2012.05.003

4. Tursz A, Crost M, Gerbouin-Rérolle P, Cook JM (2010) Underascertainment of child abuse fatalities in France: Retrospective analysis of judicial data to assess underreporting of infant homicides in mortality statistics. Child Abuse Negl 34:534-544. https://doi.org/10.1016/j.chiabu.2009.12.005

5. De Volder J. (1812) Essai médico-légal sur la docimasie des poumons ; Thèse

6. Knight B, Saukko PJ (2004) Knight's Forensic pathology, 3rd ed. Arnold; Distributed in the United States of America by Oxford University Press, London : New York

7. Egger C, Vaucher P, Doenz F, et al (2012) Development and validation of a postmortem radiological alteration index: the RA-Index. Int J Legal Med 126:559-566.

https://doi.org/10.1007/s00414-012-0686-6

8. (1976) A pathognomonic sign of intra-uterine death. Am J Obstet Gynecol 124:430. https://doi.org/10.1016/0002-9378(76)90107-1

9. Baglivo M, Winklhofer S, Hatch GM, et al (2013) The rise of forensic and post-mortem radiology_Analysis of the literature between the year 2000 and 2011. J Forensic Radiol Imaging 1:3-9. https://doi.org/10.1016/j.jofri.2012.10.003

10. Gorincour G, Sarda-Quarello L, Laurent P-E, et al (2015) The future of pediatric and perinatal postmortem imaging. Pediatr Radiol 45:509-516.

https://doi.org/10.1007/s00247-014-3266-8

11. Guddat SS, Gapert R, Tsokos M, Oesterhelweg L (2013) Proof of live birth using postmortem multislice computed tomography (pmMSCT) in cases of suspected neonaticide: advantages of diagnostic imaging compared to conventional autopsy. Forensic Sci Med Pathol 9:3-12. https://doi.org/10.1007/s12024-012-9361-y

12. Sieswerda-Hoogendoorn T, Soerdjbalie-Maikoe V, Maes A, van Rijn RR (2013) The value of post-mortem CT in neonaticide in case of severe decomposition: Description of 12 cases. Forensic Sci Int 233:298-303. https://doi.org/10.1016/j.forsciint.2013.09.023

13. Michiue T, Ishikawa T, Kawamoto O, et al (2013) Postmortem CT investigation of air/gas distribution in the lungs and gastrointestinal tracts of newborn infants: A serial case study with regard to still- and live birth. Forensic Sci Int 226:74-80. https://doi.org/10.1016/j.forsciint.2012.12.011 
14. Adamsbaum C, Rey-Salmon C (2013) Maltraitance chez l'enfant. Médecine sciences publications-Lavoisier, Paris

15. Große Ostendorf A-L, Rothschild MA, Müller AM, Banaschak S (2013) Is the lung floating test a valuable tool or obsolete? A prospective autopsy study. Int J Legal Med 127:447-451. https://doi.org/10.1007/s00414-012-0727-1

16. Schulte B, Rothschild MA, Vennemann M, Banaschak S (2013) Examination of (suspected) neonaticides in Germany: a critical report on a comparative study. Int J Legal Med 127:621-625. https://doi.org/10.1007/s00414-013-0841-8

17. Griest K Pediatric Homicide : medical investigation, CRC Press

18. Beauthier J-P (2007) Traité de Médecine Legale, 2ème Edition. de Boeck

19. Moar JJ (1997) The hydrostatic test--a valid method of determining live birth? Am J Forensic Med Pathol 18:109-110

20. Levy AD, Harcke HT, Mallak CT (2010) Postmortem Imaging: MDCT Features of Postmortem Change and Decomposition. Am J Forensic Med Pathol 31:12-17. https://doi.org/10.1097/PAF.0b013e3181c65e1a

21. Laurent P-E, Coulange M, Bartoli C, et al (2013) Appearance of gas collections after scuba diving death: a computed tomography study in a porcine model. Int J Legal Med 127:177-184. https://doi.org/10.1007/s00414-011-0662-6

22. Laurent P-E, Coulange M, Mancini J, et al (2014) Postmortem CT appearance of gas collections in fatal diving accidents. AJR Am J Roentgenol 203:468-475. https://doi.org/10.2214/AJR.13.12063

23. Dettmeyer RB (2011) Forensic Histopathology. Springer Berlin Heidelberg, Berlin, Heidelberg

24. Robinson C, Biggs MJ, Amoroso J, et al (2014) Post-mortem computed tomography ventilation; simulating breath holding. Int J Legal Med 128:139-146. https://doi.org/10.1007/s00414-013-0943-3

25. Barber JL, Sebire NJ, Chitty LS, et al (2015) Lung aeration on post-mortem magnetic resonance imaging is a useful marker of live birth versus stillbirth. Int J Legal Med 129:531-536. https://doi.org/10.1007/s00414-014-1125-7

26. Shiotani S, Kohno M, Ohashi N, et al (2004) Non-traumatic postmortem computed tomographic (PMCT) findings of the lung. Forensic Sci Int 139:39-48. https://doi.org/10.1016/j.forsciint.2003.09.016

27. Filograna L, Thali MJ (2017) Post-mortem CT imaging of the lungs: pathological versus non-pathological findings. Radiol Med (Torino) 122:902-908. https://doi.org/10.1007/s11547-017-0802-2

28. Non-specific post-mortem modifications on whole-body post-mortem computed tomography in sudden unexpected death in infancy - Journal of Forensic Radiology and 
Imaging. http://www.jofri.net/article/S2212-4780(15)00013-1/abstract. Accessed 13 Sep 2015

29. Kawasumi Y, Usui A, Hosokai Y, et al (2015) Post-mortem computed tomography findings of the lungs: Retrospective review and comparison with autopsy results of 30 infant cases. Eur J Radiol 84:721-725. https://doi.org/10.1016/j.ejrad.2014.12.002

De Volder (J.-P.) Essai médico-légal sur la docimasie des poumons. Thèses de Paris, 1812, in$4, n^{\circ} 114$

Spalding (1922) A pathognomonic sign of intrauterine death. Surgery, Gynecology and Obstetrics, 1922, xxxiv, 754

Griest K (2010) Pediatric homicide: medical investigation. CRC Press, Boca Raton

Beauthier J-P (2007) Traité de Médecine Legale, 2ème Edition. de Boeck. pp389-402 


\section{Legends}

\section{Figure 1: Livebirth case}

PMCT axial (a) and coronal (b) views: diffuse ground glass aspect of the aerated pulmonary parenchyma.

(c) VR reconstruction of the chest with presence of air in both lungs; presence of a bubble gas in the stomach, but absence of aeration behind the duodeno-jejunal junction.

(d) Microscopic aspect of the lung (Hematein Eosin Saffron (HES) magnification x 200); diffuse and homogeneous expansion of the pulmonary alveoli.

\section{Figure 2: Stillbirth case}

PMCT axial (a) and coronal (b) views; high density of the whole pulmonary parenchyma without visible aeration.

(c) VR reconstruction of the chest without any trace of air in both whole lungs; presence of a little bubble gas in the stomach.

(d) Microscopic aspect of the lung (HES, magnification x 200); absence of expansion of the pulmonary alveoli.

\section{Figure 3: Livebirth case who received CPR}

PMCT axial (a) and coronal (b) views; presence of distal ground glass opacities, alternating with non-systematized condensations.

(c) VR reconstruction of the chest: presence of inhomogeneous aerated zones in the lungs; aeration of the gastro intestinal tract behind the duodeno-jejunal junction.

(d) Microscopic aspect of the lung (HES, magnification x5): diffuse and extensive but heterogenous aeration of the alveoli. Alternation of poorly aerated zones and predominant 
well-aerated zones, with some polycyclic cavities of acute emphysema due to rupture of alveolar-capillary membranes.

(e) Microscopic aspect of the lung: upper image (HES, magnification x100): numerous neutrophils and scattered scales in the lumen of the alveoli; exogenous brownish and flaky material, compatible with meconium. Bronchi are filled with neutrophils. Lower image: rupture of interalveolar walls evocative of acute emphysema.

\section{Figure 4: Stillbirth case who received CPR}

PMCT axial (a) and coronal (b) views: small areas of distal ground glass opacities, mainly in the basis of the pulmonary fields. The major part of the parenchyma is condensed.

(c) VR reconstruction of the chest: distal and inconspicuous presence of air in pulmonary fields; aeration of the gastro-intestinal tract mainly in the stomach and a small volume behind the duodeno-jejunal junction. 


\begin{tabular}{|c|c|c|c|c|c|c|c|c|c|c|}
\hline \multirow[t]{2}{*}{ case } & \multirow{2}{*}{$\begin{array}{c}\mathrm{Se} \\
\mathrm{x}\end{array}$} & \multirow{2}{*}{$\begin{array}{c}\text { Gestational term } \\
\text { (amenorrhea } \\
\text { weeks) }\end{array}$} & \multirow{2}{*}{$\begin{array}{l}\text { Estimated delay } \\
\text { between birth and } \\
\text { discovery (hours) }\end{array}$} & \multirow{2}{*}{$\begin{array}{l}\text { Post mortem } \\
\text { changes }\end{array}$} & \multicolumn{2}{|c|}{ Lung's weight (g) } & \multirow{3}{*}{$\begin{array}{l}\text { Result of } \\
\text { Hydrostatic } \\
\text { test } \\
+\end{array}$} & \multirow{3}{*}{\begin{tabular}{|l|} 
Cause of death \\
$\begin{array}{l}\text { lack of care, } \\
\text { head and abdominal trauma }\end{array}$ \\
\end{tabular}} & \multirow{3}{*}{$\begin{array}{l}\text { pathological } \\
\text { examination } \\
\text { available } \\
\text { No }\end{array}$} & \multirow{3}{*}{\begin{tabular}{|l|} 
Conclusion \\
Livebirth
\end{tabular}} \\
\hline & & & & & $\mathrm{RL}$ & $\mathrm{LL}$ & & & & \\
\hline 1 & $M$ & $35-36$ & $<36$ & Livor mortis & 25 & 15 & & & & \\
\hline 2 & $\mathrm{~F}$ & 41 (term) & $<12$ & $\begin{array}{l}\text { Rigor mortis } \\
\text { Livor mortis }\end{array}$ & 35 & 25 & + & lack of care & yes & Livebirth \\
\hline 3* & $M$ & 41 (term) & $<4$ & none & 30 & 25 & - & undefined & Yes & Stillbirth \\
\hline 4 & $M$ & 30 & unknown & $\begin{array}{l}\text { Focal skin } \\
\text { slippage }\end{array}$ & 17 & 17 & - & undefined & Yes & Stillbirth \\
\hline 5 & $\mathrm{~F}$ & 38 (term) & unknown & $\begin{array}{l}\text { Focal skin } \\
\text { slippage }\end{array}$ & 28 & 22 & + & $\begin{array}{l}\text { hemorrhagic asphyxia, lack of } \\
\text { medical care, hypothermia }\end{array}$ & Yes & Livebirth \\
\hline 6 & $M$ & 36 & $<12$ & $\begin{array}{l}\text { Rigor mortis } \\
\text { Livor mortis }\end{array}$ & 29 & 34 & + & mechanical asphyxia & Yes & Livebirth \\
\hline 7 & $\mathrm{~F}$ & $33-36$ & unknown & Maceration & 14 & 10 & - & In utero fetal death & Yes & Stillbirth \\
\hline $8^{*}$ & $\mathrm{~F}$ & 41 (term) & $<4$ & none & 43 & 34 & + & Massive meconial inhalation & Yes & Livebirth \\
\hline 9 & $\mathrm{~F}$ & $24-26$ & $<12$ & Livor mortis & - & - & - & undefined & No & Stillbirth \\
\hline 10 & $\mathrm{~F}$ & 36 & $<6$ & Livor mortis & 27 & 23 & - & undefined & No & Stillbirth \\
\hline 11 & $\mathrm{~F}$ & $32-36$ & $<12$ & Livor mortis & - & - & + & undefined & No & Livebirth \\
\hline
\end{tabular}

* cases with cardiopulmonary resuscitation; F, Female; M, Male; RL, Right lung; LL, left lung

+ , positive ; -, negative 
Table 2: CT findings

\begin{tabular}{|c|c|c|c|c|c|c|c|}
\hline \multirow[t]{2}{*}{ Case } & \multirow{2}{*}{$\begin{array}{l}\text { Qualitative evaluation } \\
\text { of the lung's aeration }\end{array}$} & \multicolumn{3}{|c|}{ Mean density (Hounsfield Units) } & \multirow{2}{*}{$\begin{array}{c}\text { Aeration of trachea } \\
\text { and bronchi }\end{array}$} & \multirow{2}{*}{$\begin{array}{c}\text { Aeration of digestive } \\
\text { tract }\end{array}$} & \multirow[b]{2}{*}{ Conclusion } \\
\hline & & Right Lung & Left Lung & Global & & & \\
\hline 2 & Present & -98 & -122 & -110 & + & Stomach & Livebirth \\
\hline 4 & Absent & 36 & 41 & 39 & + & Stomach & Stillbirth \\
\hline 5 & Present & -4 & -144 & -74 & + & Stomach + jejunum & Livebirth \\
\hline 6 & Present & -241 & -225 & -233 & + & Stomach & Livebirth \\
\hline 9 & Absent & 52 & 50 & 51 & - & Stomach & Stillbirth \\
\hline 10 & Absent & 42 & 46 & 44 & - & Stomach & Stillbirth \\
\hline 11 & Present & -382 & -327 & -355 & + & Stomach + Jejunum & Livebirth \\
\hline
\end{tabular}

* cases with cardiopulmonary resuscitation

+ , positive ; -, negative 
Legends

$\underline{\text { Figure 1: Livebirth case }}$

PMCT axial (a) and coronal (b) views: diffuse ground glass aspect of the aerated pulmonary parenchyma.

(c) VR reconstruction of the chest with presence of air in both lungs; presence of a bubble gas in the stomach, but absence of aeration behind the duodeno-jejunal junction.

(d) Microscopic aspect of the lung (Hematein Eosin Saffron (HES) magnification x 200); diffuse and homogeneous expansion of the pulmonary alveoli. 


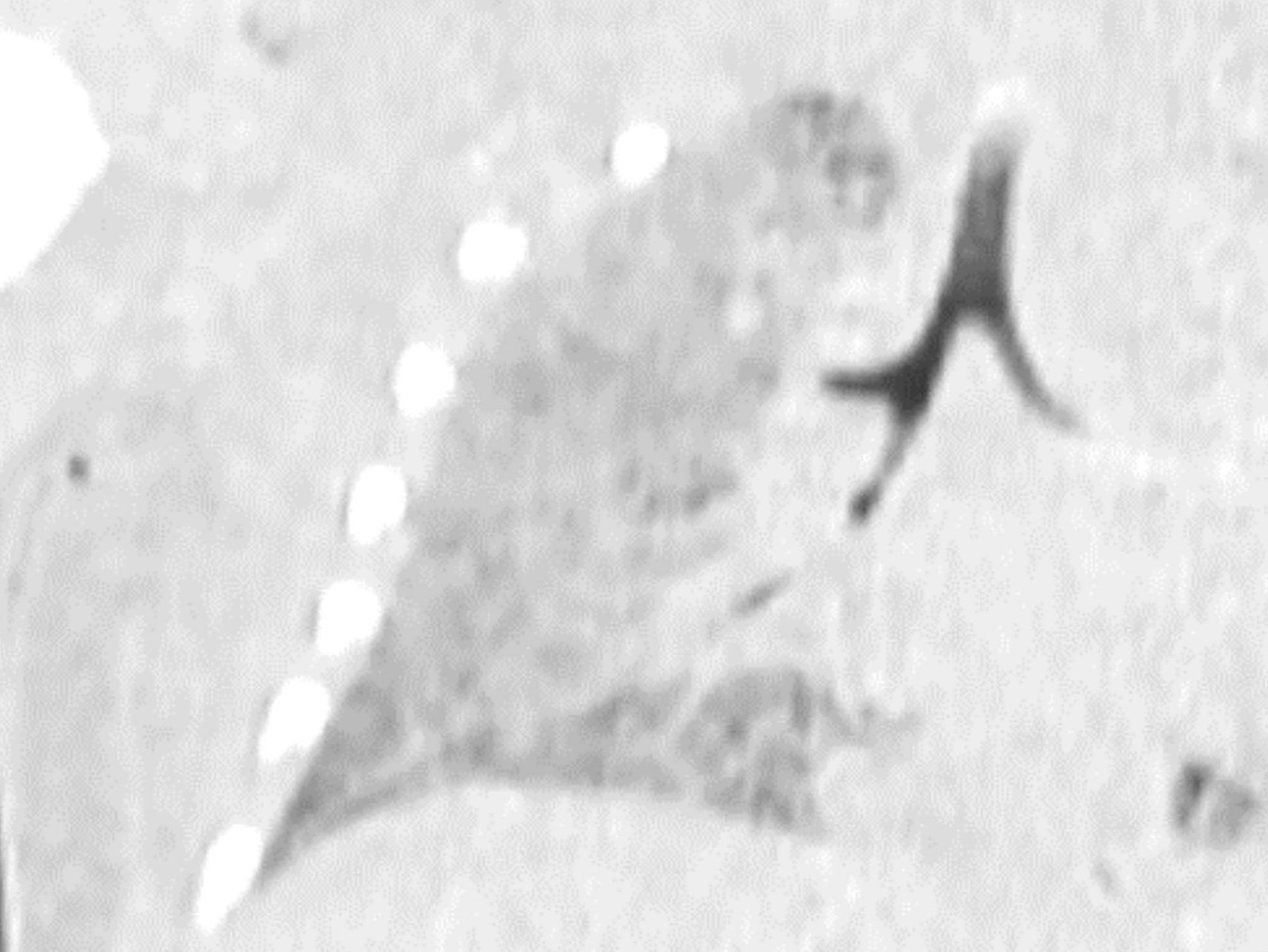


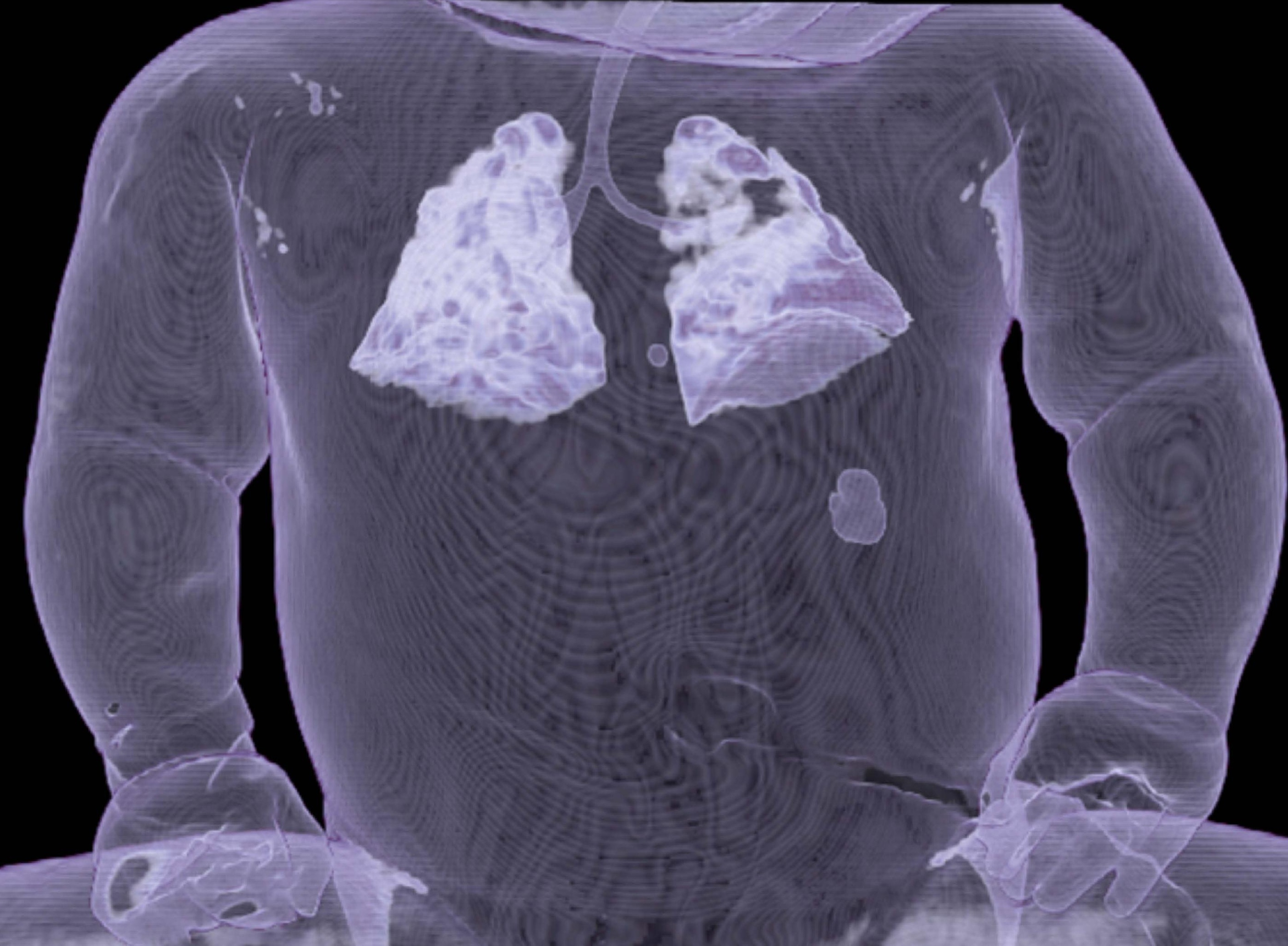


Legends

Figure 2: Stillbirth case

PMCT axial (a) and coronal (b) views; high density of the whole pulmonary parenchyma without visible aeration.

(c) VR reconstruction of the chest without any trace of air in both whole lungs; presence of a little bubble gas in the stomach.

(d) Microscopic aspect of the lung (HES, magnification x 200); absence of expansion of the pulmonary alveoli. 



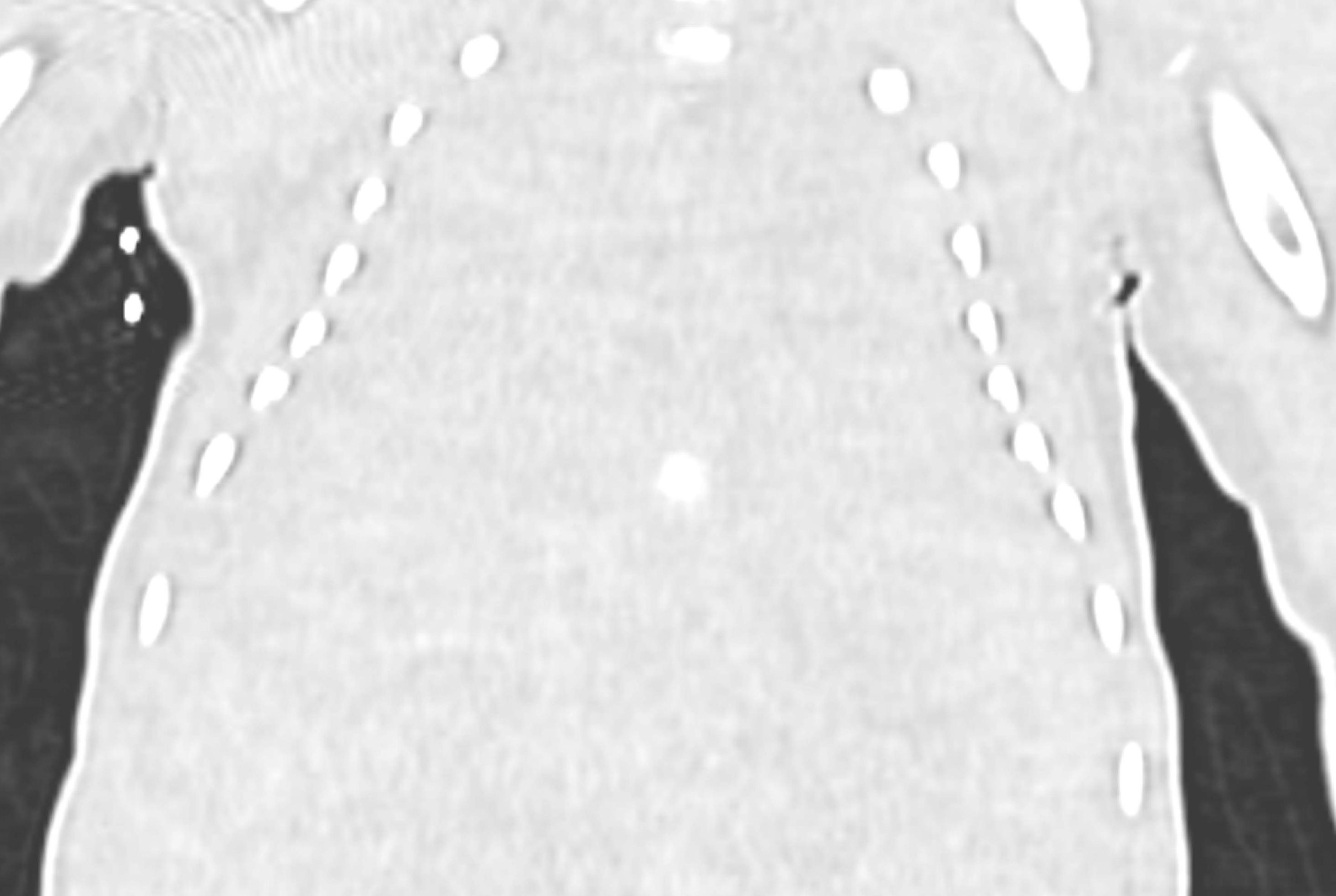




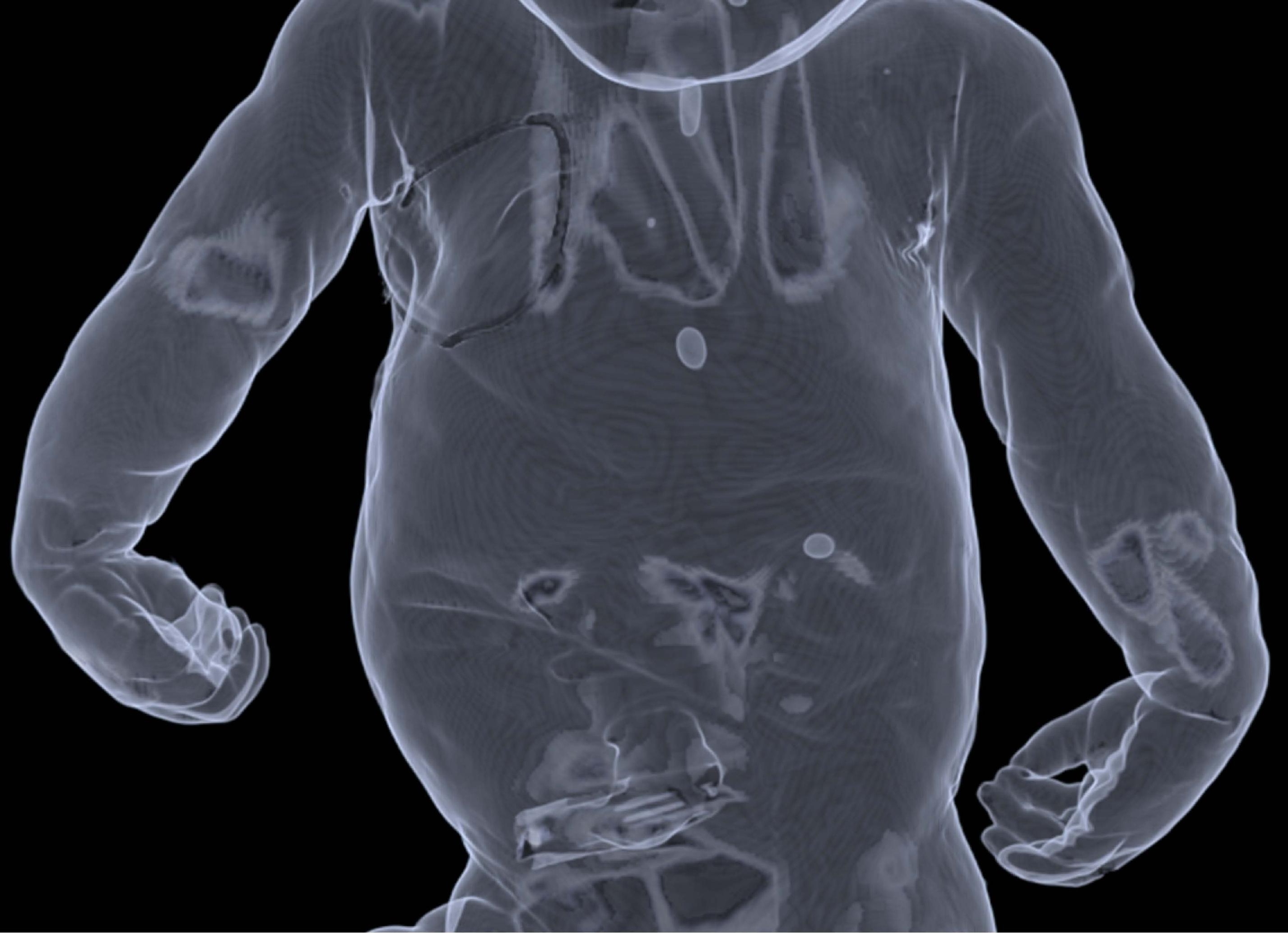




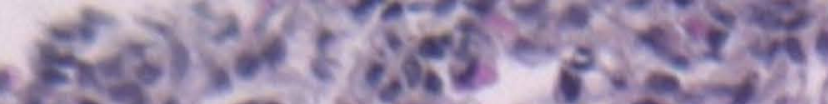

F.

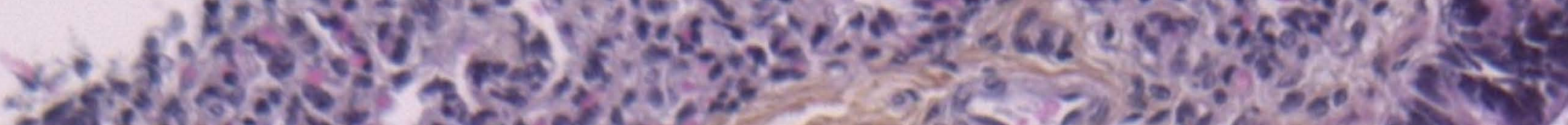

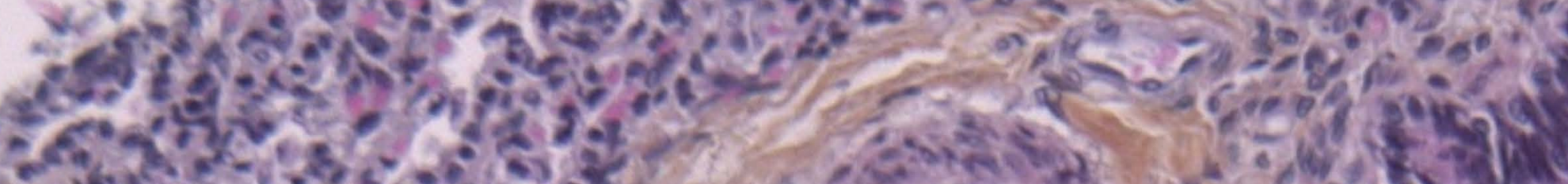

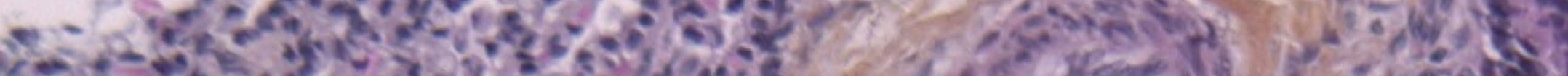

6 a.

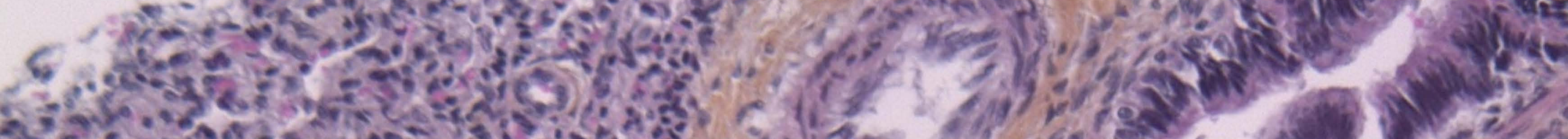

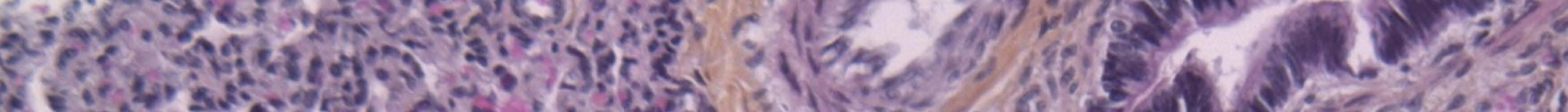

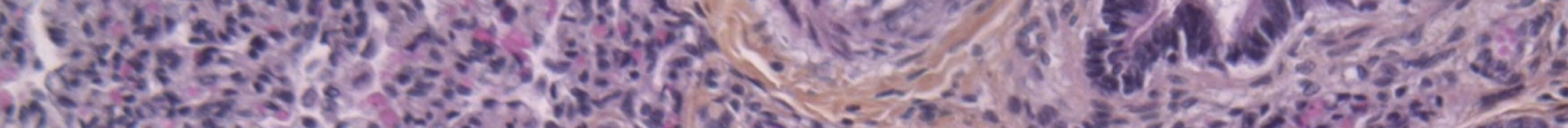

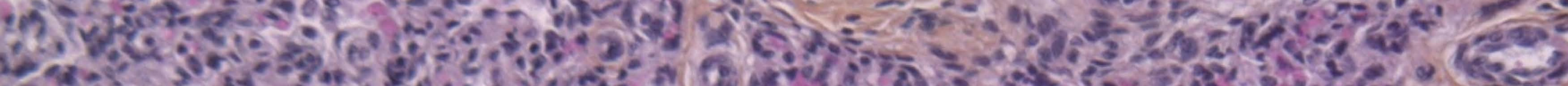

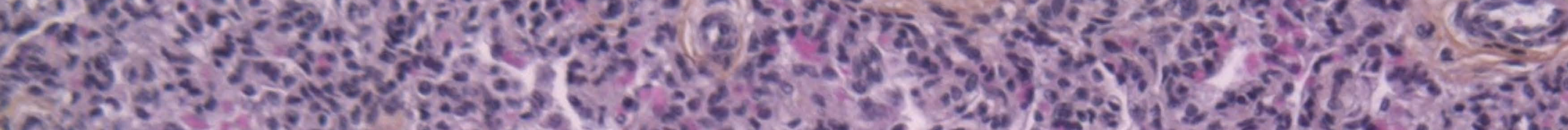



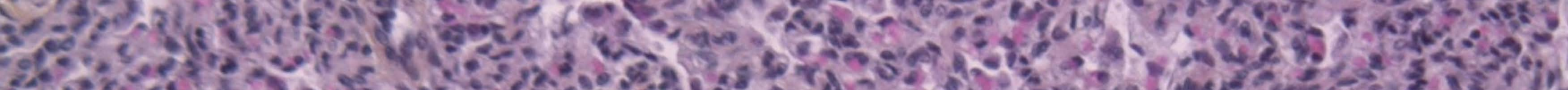

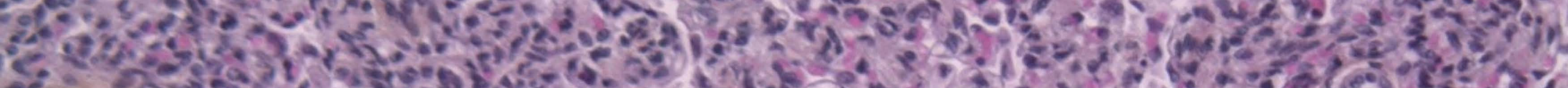

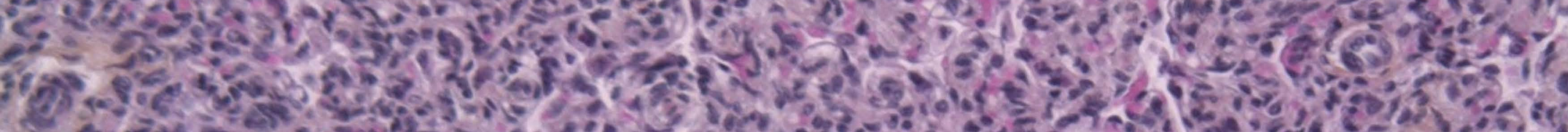

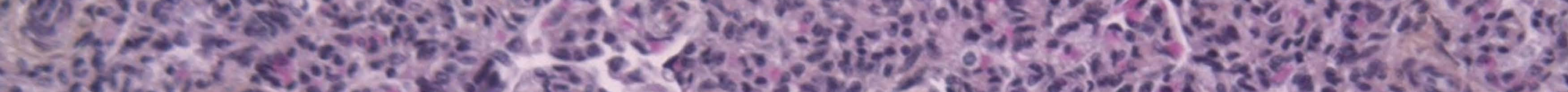

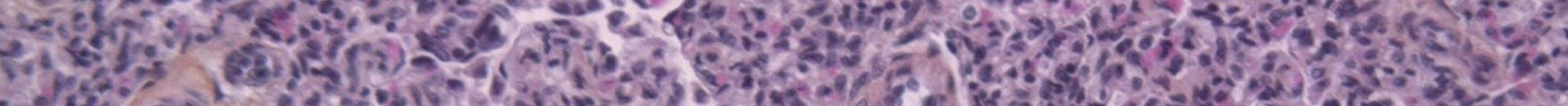

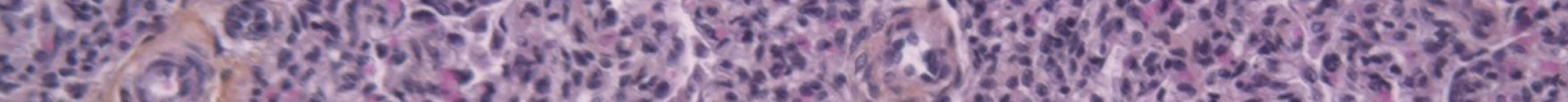
3.28
35

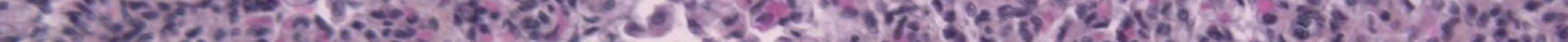


Legends

Figure 3: Livebirth case who received CPR

PMCT axial (a) and coronal (b) views; presence of distal ground glass opacities, alternating with non-systematized condensations.

(c) VR reconstruction of the chest: presence of inhomogeneous aerated zones in the lungs; aeration of the gastro intestinal tract behind the duodeno-jejunal junction.

(d) Microscopic aspect of the lung (HES, magnification x5): diffuse and extensive but heterogenous aeration of the alveoli. Alternation of poorly aerated zones and predominant well-aerated zones, with some polycyclic cavities of acute emphysema due to rupture of alveolar-capillary membranes.

(e) Microscopic aspect of the lung: upper image (HES, magnification x100): numerous neutrophils and scattered scales in the lumen of the alveoli; exogenous brownish and flaky material, compatible with meconium. Bronchi are filled with neutrophils. Lower image: rupture of interalveolar walls evocative of acute emphysema. 


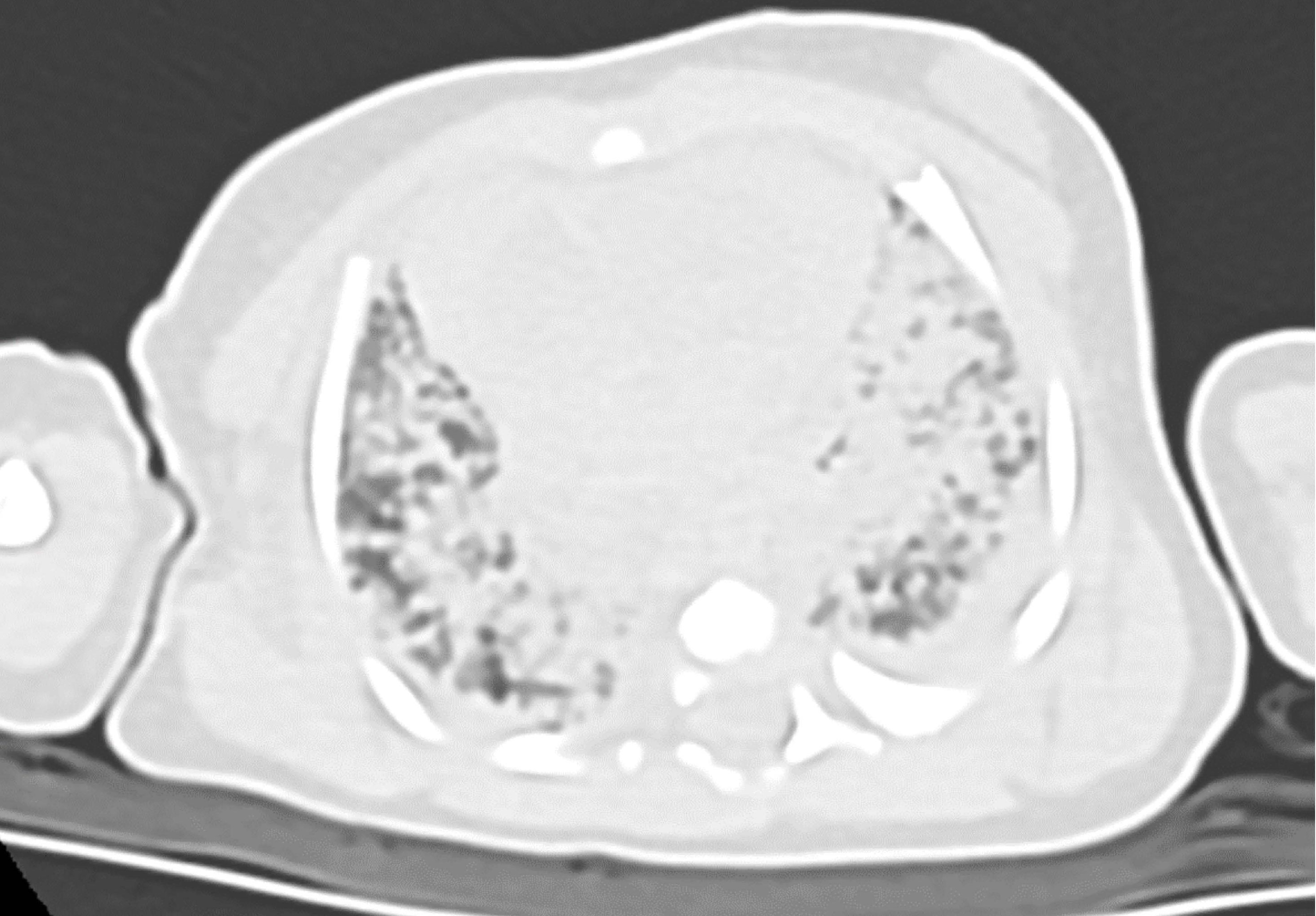


.
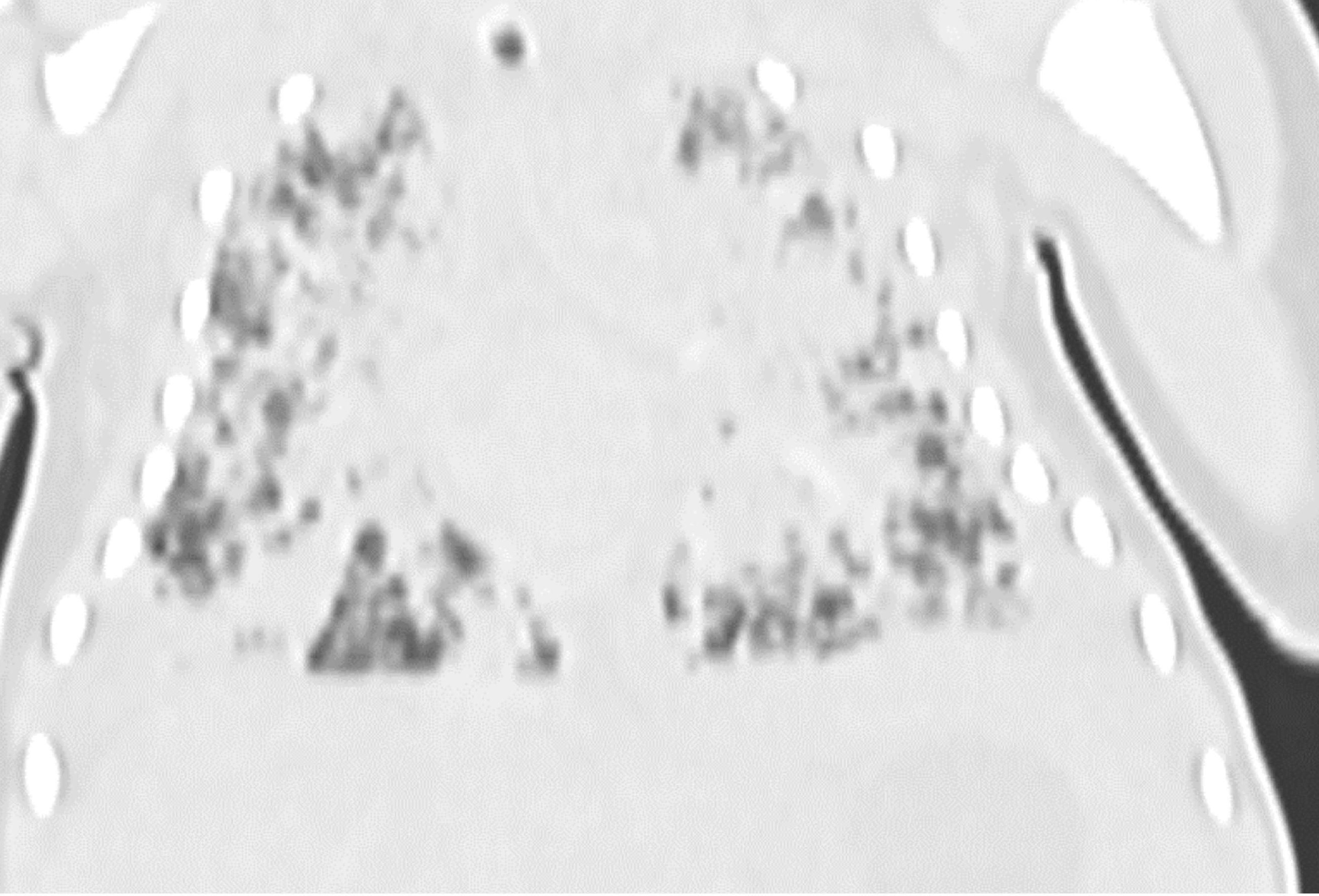


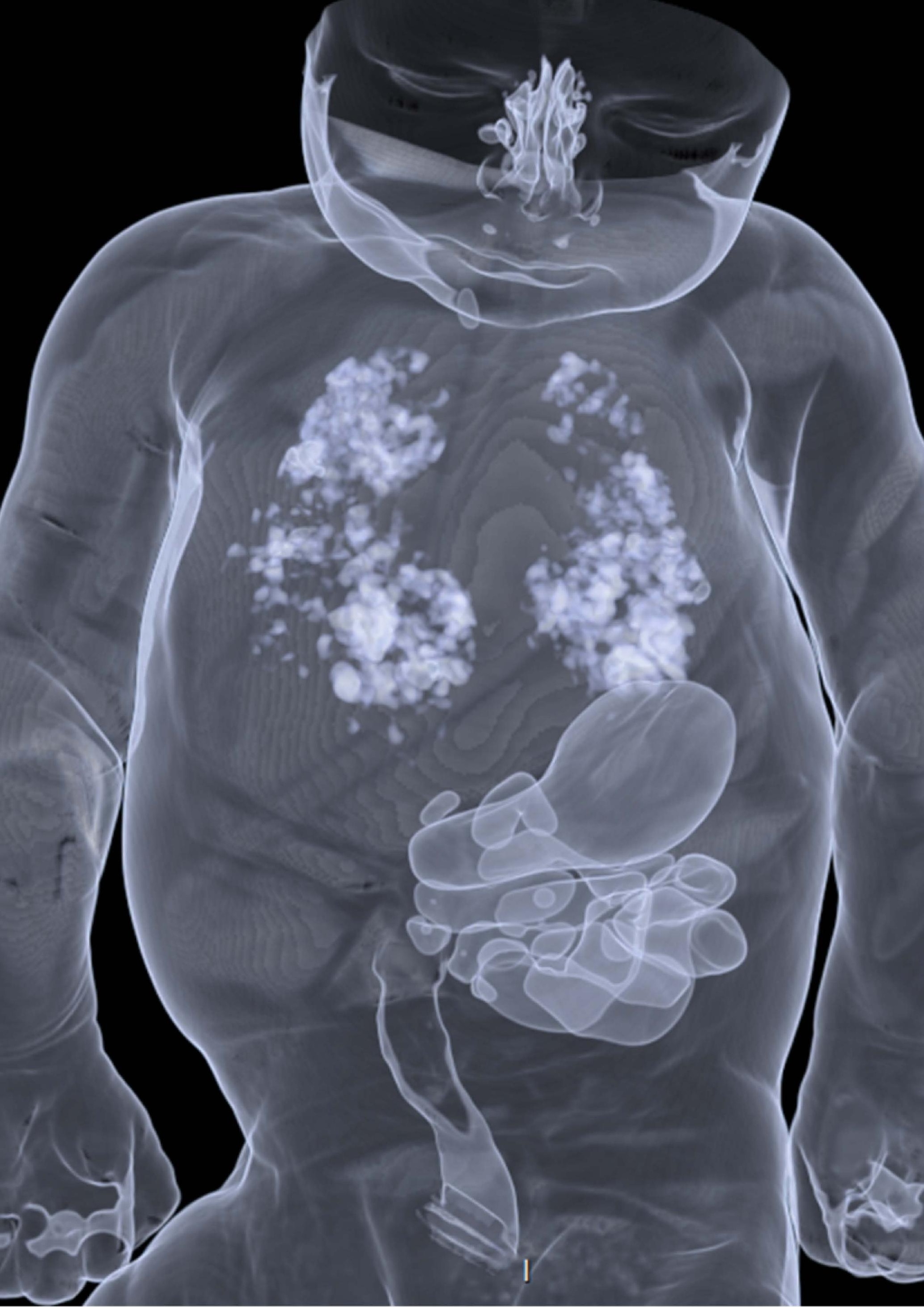




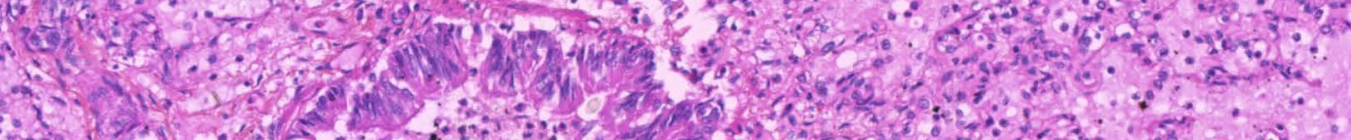

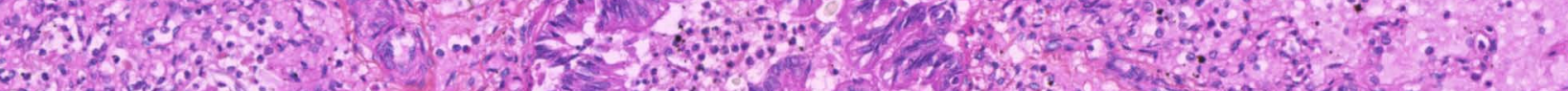
(5.m.

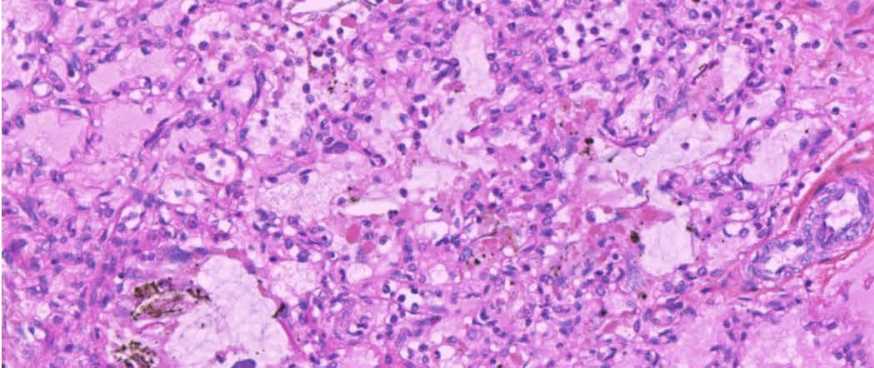

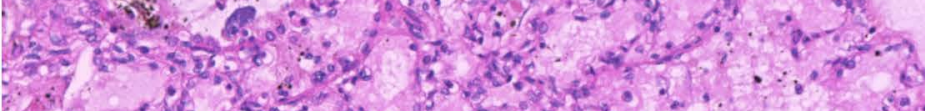

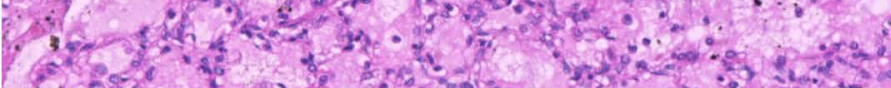

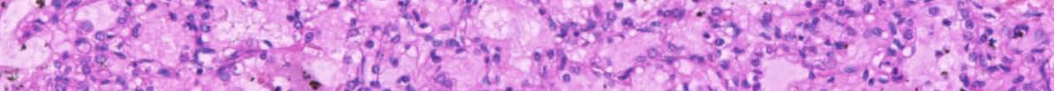
F.

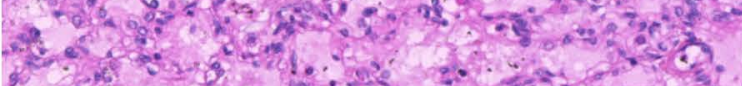

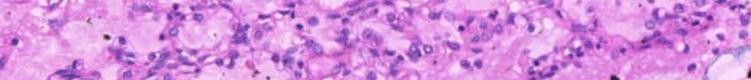

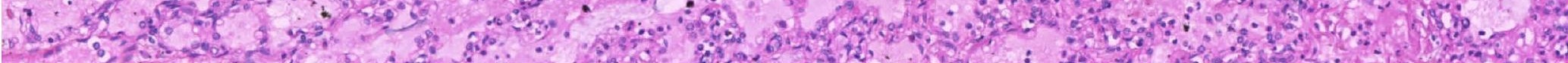

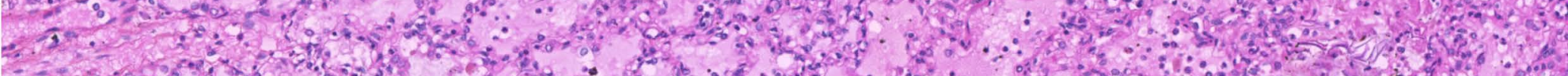

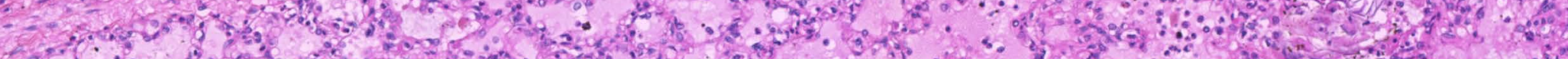

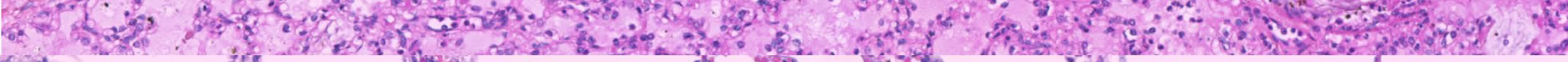

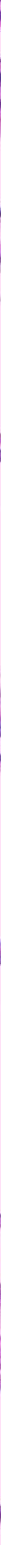


Figure 4: Stillbirth case who received CPR

PMCT axial (a) and coronal (b) views: small areas of distal ground glass opacities, mainly in the basis of the pulmonary fields. The major part of the parenchyma is condensed.

(c) VR reconstruction of the chest: distal and inconspicuous presence of air in pulmonary

fields; aeration of the gastro-intestinal tract mainly in the stomach and a small volume behind the duodeno-jejunal junction. 



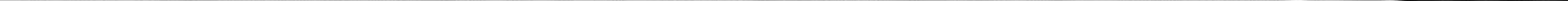




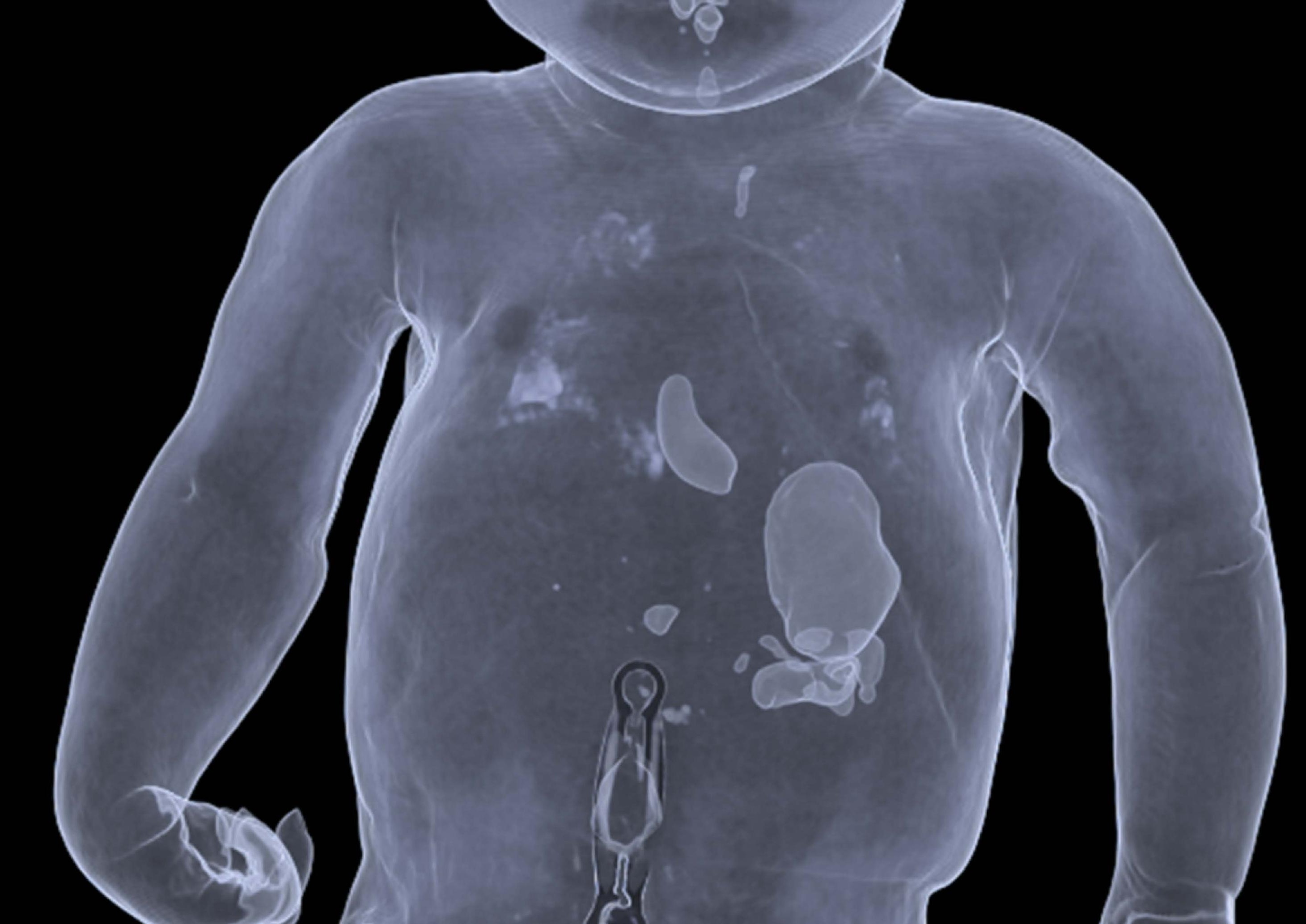




\section{Figure 5: Comparison of mean densities for stillbirth (SB) and livebirth (LB) cases $(p=0.004)$}

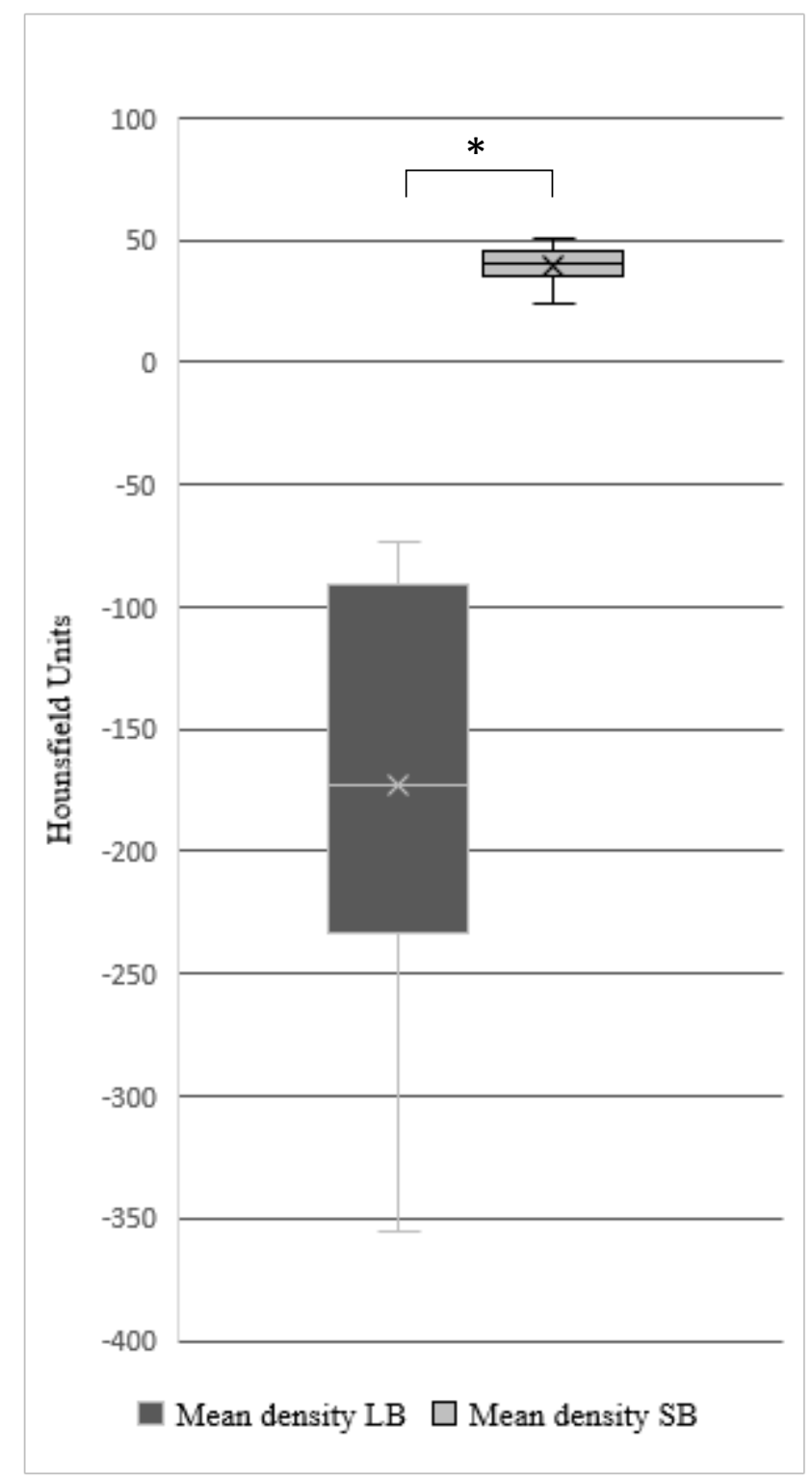

